\title{
Acute in vivo evaluation of a new stentless mitral valve
}

\author{
Jose L. Navia, MD, ${ }^{a}$ Kazuyoshi Doi, MD, ${ }^{\text {b }}$ Fernando A. Atik, MD, ${ }^{a}$ Kiyotaka Fukamachi, MD, PhD,
}

Michael W. Kopcak Jr, BA, Raymond Dessoffy, AA, ${ }^{\text {b }}$ Pablo Ruda-Vega, MD, ${ }^{\text {a }}$ Mario Garcia, MD, ${ }^{c}$ Penny L. Houghtaling, MS, ${ }^{d}$ Maureen Martin, RDCS, ${ }^{\mathrm{c}}$ Eugene H. Blackstone, MD, a,d Patrick M. McCarthy, MD, and Bruce W. Lytle, MD ${ }^{\mathrm{a}}$

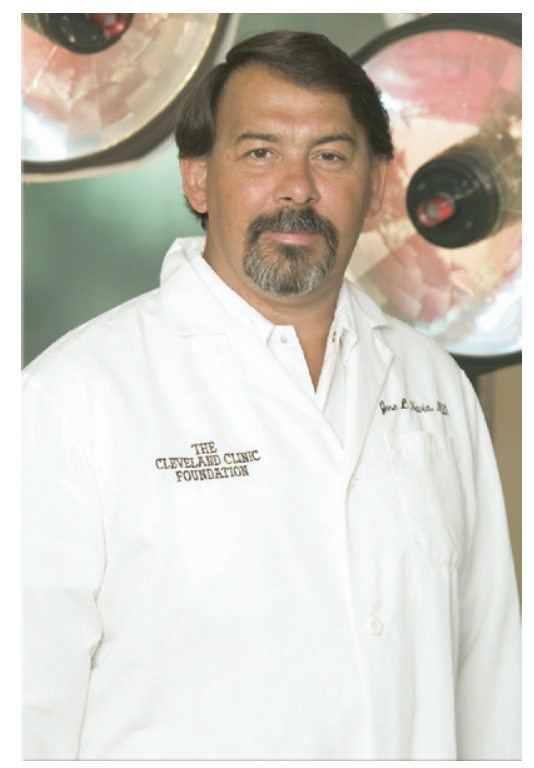

Dr Navia

See related editorial on page 861.

丹 Supplemental material is available online.

Objectives: We have developed a stentless pericardial mitral valve prosthesis in 2 configurations; the purposes of this acute study in sheep were to assess (1) valve design and implant technique; (2) valve performance; and (3) acute effects on postimplant left ventricular function.

Methods: A stentless bovine pericardial bileaflet valve was developed with the intent to preserve annular-papillary muscle continuity. This valve, in 2 configurations - with $(\mathrm{n}=5)$ and without $(\mathrm{n}=5)$ flap chordae-was implanted in 10 sheep (mean weight $73 \pm 9 \mathrm{~kg}$ ). Epicardial echocardiography was performed to assess valve performance. Load-independent left ventricular function was also estimated before implantation (baseline), 1 hour after discontinuing cardiopulmonary bypass (rest), and during dobutamine stimulation using conductance technology.

Results: Implantation was easily accomplished for both configurations. Both configurations had low transvalvular pressure (mean $2.1 \pm 1.2 \mathrm{~mm} \mathrm{Hg}$ at rest; $2.2 \pm 1.0$ $\mathrm{mm} \mathrm{Hg}$ with dobutamine stimulation with flap chordae; $1.7 \pm 0.5 \mathrm{~mm} \mathrm{Hg}$ and 1.6 $\pm 0.3 \mathrm{~mm} \mathrm{Hg}$ without flap chordae). No mitral regurgitation was observed in 8 sheep, and mild regurgitation was seen in 2 sheep. Compared with baseline, slope of maximum rate of change of left ventricular pressure-end-diastolic volume relation increased with stimulation both with flap chordae $\left(+52 \pm 41 \mathrm{~mm} \mathrm{Hg} \cdot \mathrm{s}^{-1}\right.$ - $\left.\mathrm{mL}^{-1}, P=.0005\right)$ and without $\left(+20 \pm 12 \mathrm{~mm} \mathrm{Hg} \cdot \mathrm{s}^{-1} \cdot \mathrm{mL}^{-1}, P=.003\right)$.

Conclusions: Both configurations of this newly designed stentless mitral bioprosthesis, which preserves annular-papillary muscle continuity using different novel surgical implantation techniques, demonstrated reliable valve performance, with low transvalvular pressure gradients, minimal regurgitation, and acutely preserved postimplant left ventricular function. Further chronic study is needed to verify these results and evaluate reliability of implantation procedures, biocompatibility, and durability.

Departments of Thoracic and Cardiovascular Surgery, Biomedical Engineering ${ }^{\mathrm{b}}$, Cardiovascular Medicine ${ }^{\mathfrak{c}}$, and Quantitative Health Sciences ${ }^{\mathrm{d}}$, Cleveland Clinic, Cleveland, Ohio.

Received for publication Feb 7, 2006; revisions received Nov 8, 2006; accepted for publication Nov 20, 2006.

Address for reprints: Jose L. Navia, MD, Department of Thoracic and Cardiovascular Surgery/F24, Cleveland Clinic, 9500 Euclid Avenue, Cleveland, OH 44195 (Email: naviaj@ccf.org).

J Thorac Cardiovasc Surg 2007;133:986-94 $0022-5223 / \$ 32.00$

Copyright $\odot 2007$ by The American Association for Thoracic Surgery

doi:10.1016/j.jtcvs.2006.11.044

$\mathrm{P}$ reservation of mitral annulus-papillary muscle continuity during mitral valve surgery is crucial to preserving postoperative left ventricular (LV) function and geometry. ${ }^{1,2}$ This concept has been applied to valve repair procedures, ${ }^{3-5}$ and technical modifications to preserve this continuity ${ }^{6-8}$ have been added to valve replacement to improve survival. ${ }^{7-10}$

In the aortic position, stentless bioprostheses are claimed to have lower transvalvular gradients, better hemodynamic performance, and enhanced durability compared with stented bioprostheses. ${ }^{11}$ Development of mitral stentless bioprostheses was stimulated by the same promise. Several investigators have reported experimental and clinical results of stentless bioprostheses, ${ }^{12-16}$ but these valves have rarely been implanted because of difficult design constraints imposed by anatomic and functional complexity of the native mitral valve and its subvalvular apparatus. The technical challenge of implanting mitral allografts and poor midterm clinical results due to graft failure and failure to remain competent over time have resulted 


\author{
Abbreviations and Acronyms \\ $\mathrm{CPB}=$ cardiopulmonary bypass \\ $\mathrm{F}-\mathrm{SMV}=$ stentless mitral valve with flap chordae \\ $\mathrm{LV} \quad=$ left ventricular \\ SMV $=$ stentless mitral valve
}

in a high incidence of explantation. ${ }^{17,18}$ Thus, they have not become a useful alternative to stented mitral prostheses.

Because of these shortcomings and greater understanding of the anatomy and physiologic mechanisms of the mitral valve-LV complex, a stentless mitral bioprosthesis ${ }^{19-22}$ that can be implanted with relative ease, exhibits physiologic valve performance, and preserves annular-papillary muscle continuity might be a competitive option for treating unrepairable mitral valve disease. We have developed a stentless pericardial mitral valve prosthesis in 2 configurations based on the principles of ease of implantation and preservation of mitral annulus-papillary muscle continuity. The purposes of this acute study in sheep were to assess (1) valve design and implantation technique, (2) valve performance, and (3) acute effects on postimplantation LV function.

\section{Materials and Methods}

\section{Stentless Mitral Valve Design and Implantation Techniques}

The new valve design is based on the human mitral valve $3-\mathrm{D}$ configuration. In human anatomy, the aortic and mitral valves occupy the same opening in the in the base of the left ventricle, but they lie at an angle of $40^{\circ}$ to one another. Thus, the anterior mitral leaflet forms the watershed between inflow and outflow streams of the left ventricle. Mitral leaflets form a continuous veil, attached as a muff to the circumference of the mitral annulus. The free edge of this veil hangs into the left ventricle and is split by indentations, none of which reach the annulus.

The length of annular attachment of the anterior leaflet is half that of the posterior leaflet. The maximum depth of the anterior leaflet, measured from its annular attachment to apex, is approximately twice that of the posterior leaflet. Thus, the mitral valve is conical in shape, with the inlet larger than the outlet. Because the anterior and posterior leaflets are not of equal height, the plane of the outlet orifice does not correspond with that of the annulus but is oblique, sitting in the plane of the outlet orifice to some extent, which compensates for the size discrepancy. Although the anterior and posterior leaflets differ in shape, annular attachment, and height, their surface areas are approximately equal. So, we designed and fabricated a new bileaflet stentless valve from 1 piece of $0.65 \%$ glutaraldehyde-treated bovine pericardium that mimics the human mitral valve, preserving all these anatomic features in dimension and shape.

Two configurations were developed to cope with different mitral valve pathologies. Both were designed with the implantation criteria of preserving annulus-papillary muscle continuity, maintaining the flexible physiologic contraction of the mitral annulus, removing diseased valve tissue, and replacing the valve with correct orientation and appropriate size. One configuration, the SMV (Figure 1), replaced the native mitral valve leaflets but left the native subvalvular apparatus intact. The other, F-SMV (Figure 2 ), replaced both leaflets and chordae; it has 2 flap chordae structures extending from each leaflet that are attached to the head of the native papillary muscles.

\section{Acute Animal Study}

This stentless bioprosthesis was implanted in 10 healthy Dorsett sheep (mean weight $73 \pm 9 \mathrm{~kg}$ ), 5 in each configuration. Success of implantation technique and valve performance were evaluated with epicardial echocardiography. Acute hemodynamic indices and volumetric data were also recorded before implantation (baseline), 1 hour after discontinuing cardiopulmonary bypass (CPB; rest period), and during dobutamine stimulation. The study was approved by Cleveland Clinic's Institutional Animal Care and Use Committee. All animals received humane care in compliance with the "Guide for the Care and Use of Laboratory Animals."23

\section{Valve Implantation}

Sheep were anesthetized with inhalational isoflurane and ventilated through an endotracheal tube; anesthesia was maintained with isoflurane $(0.5 \%-2.5 \%)$. Animals were placed in the right lateral position, and electrocardiography leads were attached to their extremities. After instrumentation and baseline hemodynamic measurements were obtained as detailed in Appendix E1, left thoracotomy was performed and the pericardium opened longitudinally. CPB was established with left carotid artery and pulmonary trunk-right atrium cannulation after systemic heparinization ( $3 \mathrm{mg} \cdot \mathrm{kg}^{-1}$ ). After the ascending aorta was clamped, the heart was arrested with antegrade cold blood cardioplegic solution. The left atrial free wall was then opened and mitral valve components evaluated and measured directly.

For SMV implantation, its anterior and posterior leaflets were tailored by trimming the free edges to match direct measurements of native anterior and posterior leaflet heights. SMV annulus size was chosen to match that of the native annulus. After the SMV was prepared, the native anterior leaflet was dissected from the mitral annulus and the clear zone resected, but the leaflet's rough zone and corresponding primary and secondary chordae were preserved (Figure 3, $A$ and $B$ ). The free edge of the anterior SMV leaflet was then sutured to the preserved part of the native anterior leaflet with 5-0 Ethibond (polyester; Ethicon, Inc, Somerville, NJ) continuous suture. The same procedures were repeated for the posterior leaflet, preserving native primary and secondary chordae. The inflow sewing margin was then sutured to the native mitral annulus using a 4-0 polypropylene continuous suture.

For F-SMV implantation, length between the commissural portion of the F-SMV inflow and tip of the flap chordae (F-SMV height) was determined by measuring directly the distance between the papillary muscle head and commissural portion of the native annulus on each commissural side; tips of the flap chordae were trimmed to match. F-SMV annular size was determined as for SMV. Native mitral leaflets and chordae were then totally excised, and tips of the flap chordae of the anterolateral commissural side were sutured to the 


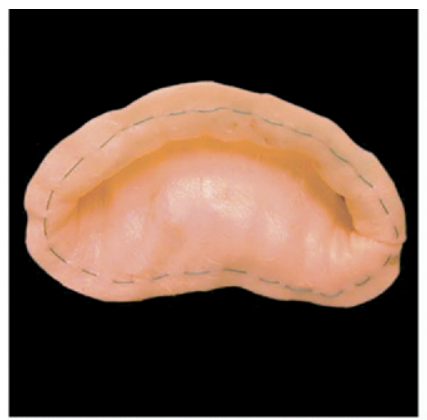

A

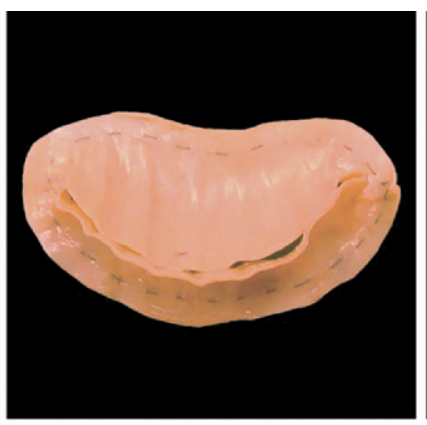

B

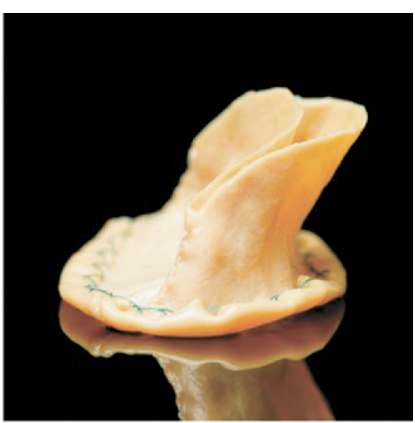

C

Figure 1. Stentless mitral valve. A, Inflow frontal view. B, Outflow frontal view. C, Lateral view.

anterolateral papillary muscle head with 4-0 Ethibond mattress suture with a pledget (Figure 3, $C$ and D). Tips of the flap chordae of the other commissural side were sutured to the posteromedial papillary muscle head. The sewing margin on the F-SMV inflow was then sutured to the native annulus as for SMV.

\section{Evaluating the Valve}

After implantation of each valve, leaflet coaptation, valve orientation, and mitral regurgitation were evaluated by infusing saline solution under pressure into the left ventricle. After closing the left atrium and unclamping the aorta, CPB was discontinued. To obtain stable hemodynamics in the post-CPB period, a low dose of norepinephrine was used in 3 of 5 sheep in the SMV group $(0.04$ $\left.\pm 0.05 \mu \mathrm{g} \cdot \mathrm{kg}^{-1} \cdot \mathrm{min}^{-1}\right)$ and 2 of 5 in the F-SMV group $(0.05$ $\left.\pm 0.07 \mu \mathrm{g} \cdot \mathrm{kg}^{-1} \cdot \mathrm{min}^{-1}\right)$.

After decannulation, the hemodynamic instrumentations (conductance catheter, flow probe, left atrial catheter) were replaced. Epicardial 2-D and Doppler echocardiography were performed to evaluate leaflet motion, regurgitation, transvalvular mean pressure gradient, LV volumes, and valve performance. Hemodynamic indices and LV volume data were recorded at steady state and after transient inferior vena cava occlusion 1 hour after discontinuing
CPB (rest). The same observations were again recorded during dobutamine ( 0.5 to $1 \mu \mathrm{g} \cdot \mathrm{kg}^{-1} \cdot \mathrm{min}^{-1}$ ) stimulation.

When all procedures were finished, the animal was killed with an overdose of intravenous pentobarbital (100 mg $\left.\cdot \mathrm{kg}^{-1}\right)$ and potassium chloride (100 mEq). At necropsy, the implanted valve was evaluated macroscopically.

\section{Data Analysis}

Details of extracting hemodynamic indices are given in Appendix E2.

All data are summarized as mean \pm SD. To account for lack of independence from multiple measurements evaluated from the same valves, longitudinal methods (SAS PROC MIXED; SAS Institute, Inc, Cary, NC) were used. ${ }^{24}$ The variables systemic vascular resistance (SVR) and slope of maximum rate of change of left ventricular pressure-end-diastolic-volume relation were logarithmically transformed to meet the distributional assumption of normality before analysis. Univariable models were initially formed to test overall changes from baseline for each hemodynamic and cardiac function measure. The F-SMV group variable was then added to assess group differences. Planned contrasts were used to test within-group changes from baseline to rest, baseline to stimulation, and rest to stimulation. Statistical analyses were performed using SAS version 8.2.

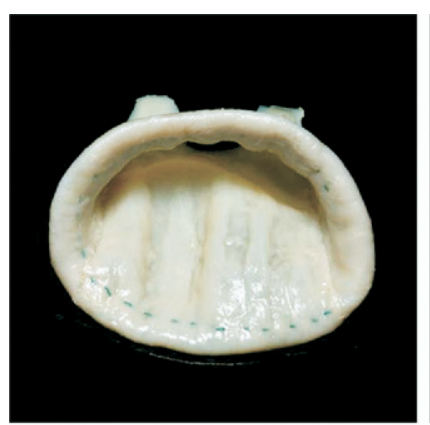

A

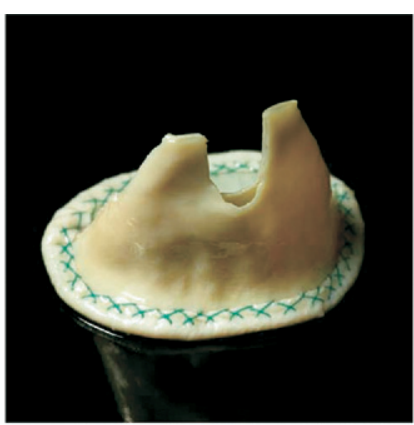

B

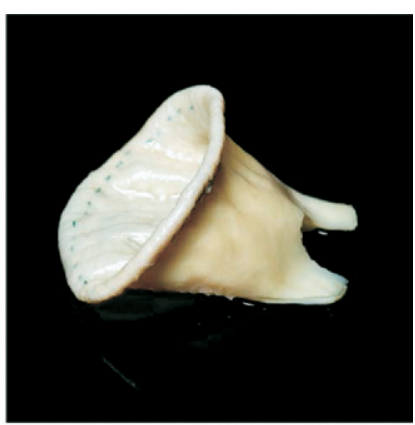

C

Figure 2. Stentless mitral valve with flap chordae. A, inflow frontal view. B, Outflow frontal view. C, Lateral view. 

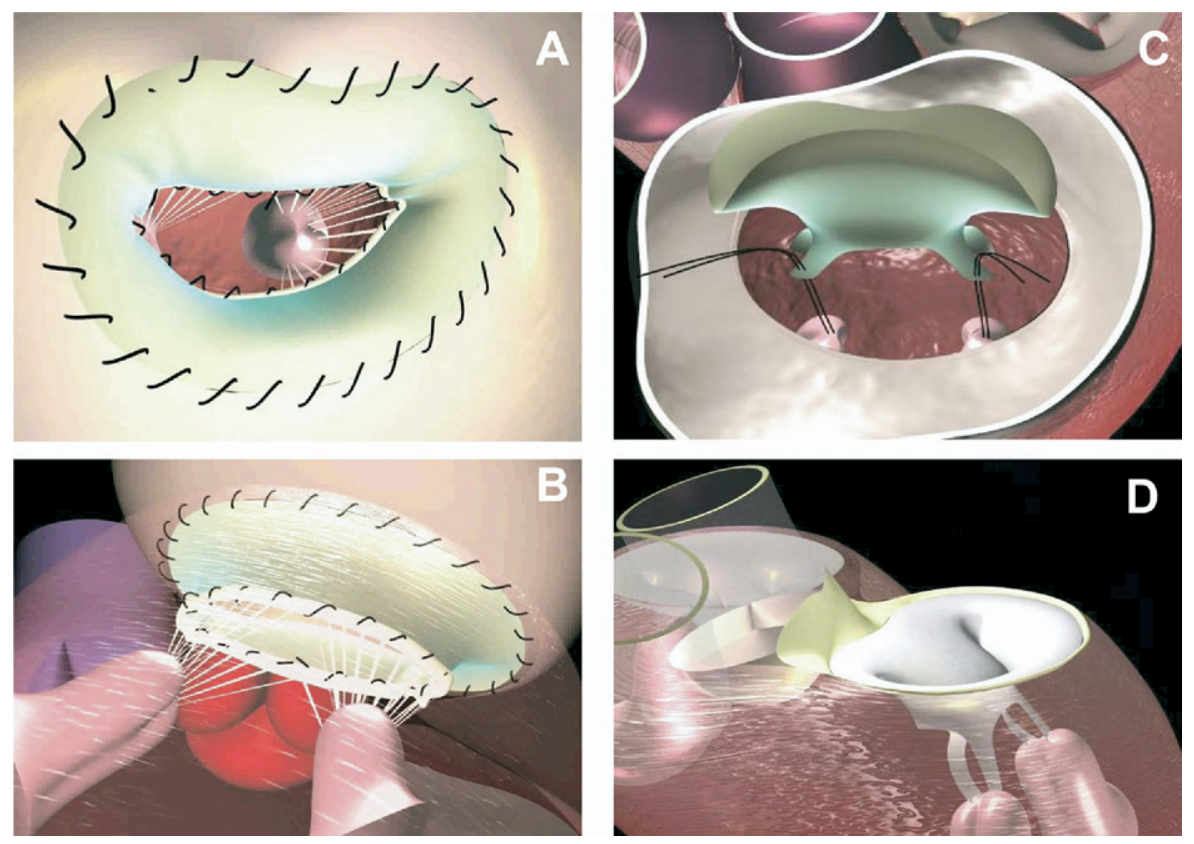

Figure 3. Schematic images of stentless valve implantation. A and B, Outflow of SMV was sutured to free edges of native leaflets, and inflow was to native mitral annulus. C and D, Flap chordae of F-SMV were sutured to papillary muscle heads, and inflow was to native mitral annulus. SMV, stentless mitral valve.

\section{Results}

\section{Implantation Feasibility and Reproducibility}

The stentless pericardial mitral valve prosthesis, in both configurations, was easily and successfully implanted. By echocardiography, both SMV and F-SMV demonstrated wide physiologic leaflet opening and secure closing without leaflet restriction, mitral stenosis, systolic anterior motion, prolapse, or tethering (Figures 4-6). In 1 of 5 SMV cases, grade 1 (mild) mitral regurgitation was detected at rest and with dobutamine stimulation; at necropsy, a fold was noted on the SMV's posterior leaflet, resulting in a segmental gap of leaflet coaptation. This fold was formed by suturing the
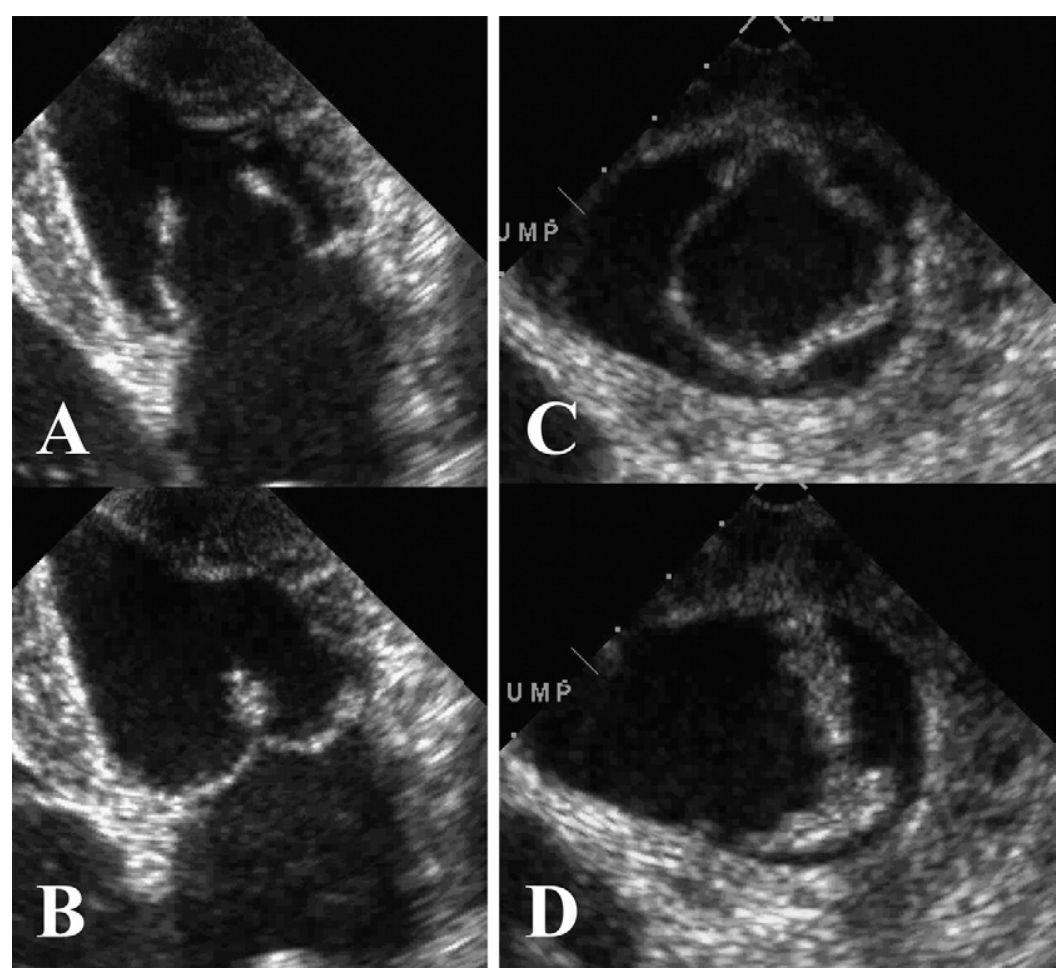

Figure 4. Stentless mitral valve (SMV): postimplant epicardial 2-D echocardiography during diastolic and systolic phases. Note wide open valve area and normal level of leaflet coaptation of the new prosthesis. A and B, 4-chamber view. C and D, Short-axis view. 

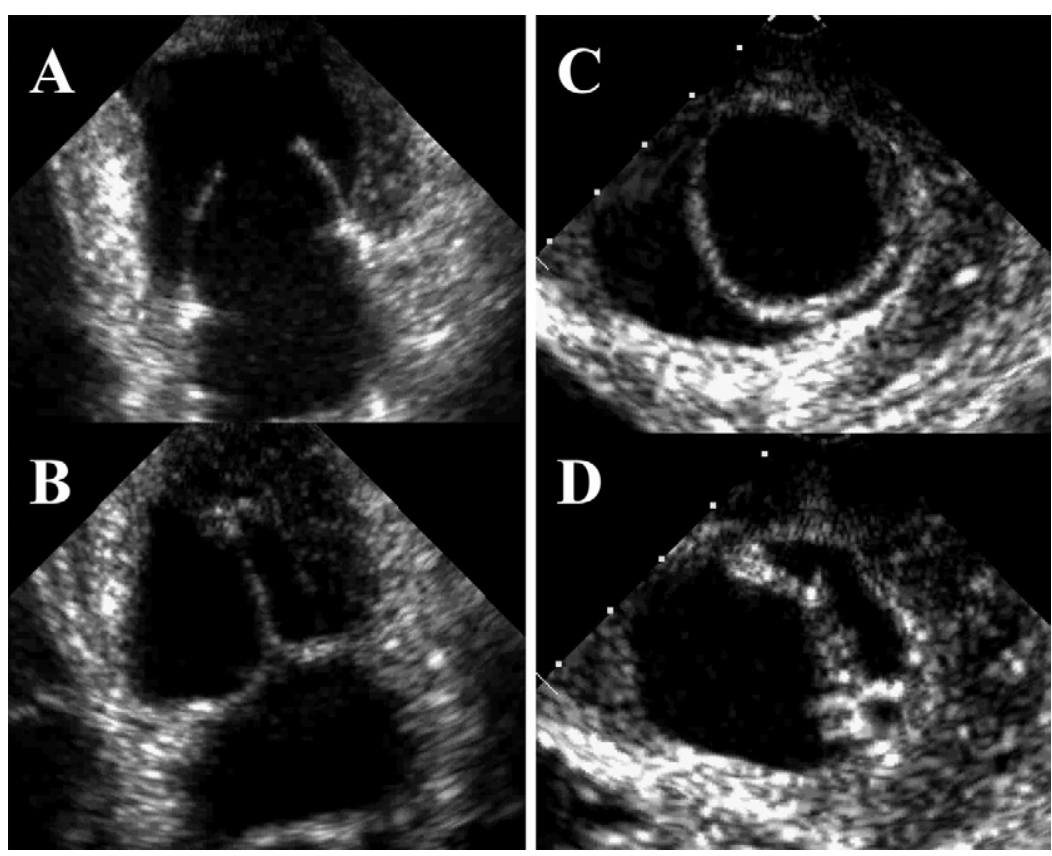

Figure 5. Stentless mitral valve with flap chordae (F-SMV): postimplant epicardial 2-D echocardiography during diastolic and systolic phases shows a large valve orifice area, with extent of opening and closing of the bioprosthesis similar to that of the native mitral valve. Anatomic mitral annular-papillary muscle integrity is preserved. A and B, 4-chamber view. C and D, Short-axis view.

redundantly wider SMV leaflet to the native leaflet. No regurgitation was found in the remaining $4 \mathrm{SMV}$ cases at rest or with stimulation. Grade 1 mitral regurgitation was detected at rest and with stimulation in 1 of 5 F-SMV cases. Regurgitation originated from the space between the flap chordae that seemed to be formed by the difference in their lengths on the same commissural side. No regurgitation was detected at rest or with stimulation in the remaining 4 of 5 F-SMV cases.

\section{Acute Valve Performance}

Mean transvalvular pressure gradient was low (SMV: $1.7 \pm$ $0.5 \mathrm{~mm} \mathrm{Hg}$ at rest, $1.6 \pm 0.3 \mathrm{~mm} \mathrm{Hg}$ with stimulation; F-SMV: $2.1 \pm 1.2 \mathrm{~mm} \mathrm{Hg}$ at rest, $2.2 \pm 1.0 \mathrm{~mm} \mathrm{Hg}$ with stimulation). No statistically significant differences were detected between rest and stimulation (SMV: $P=.6$; FSMV: $P=.8)$ or between SMV and F-SMV $(P=.3)$.

Hemodynamics at baseline and acutely postimplant at rest and with dobutamine stimulation are summarized in Table 1. Heart rate increased with stimulation in both groups. LV end-diastolic pressure remained at baseline level except for a decrease with stimulation in the SMV group. After valve implantation, cardiac output and stroke volume were lower and pulmonary capillary wedge and left atrial pressures higher in both groups.

\section{Postimplantation LV Function}

$\mathrm{LV}$ volumes were lower after valve replacement at both rest and exercise, as was LV stroke work (Table E1 and Figure
E1). However, load-independent indices of contractility were preserved in both groups (Figures 7 and 8), as was LV efficiency (Figure 8).

\section{Discussion}

\section{Feasibility and Reproducibility}

The 2 configurations of the novel stentless mitral valve presented in this report were simply and physiologically designed to reproduce features of the native human mitral valve. They employ anatomically and functionally advanced concepts of preserving annulus-papillary muscle continuity. Implantation techniques were relatively easy, feasible, and reproducible. We believe that ease of implantation and good performance of the SMV stems from not using the papillary muscles as a supporting mechanism for the prosthesis. For the F-SMV, ease and reproducibility of the implant arise because there are only 2 flap chordae extensions, and these are sutured to the anterior side of each papillary muscle head, a simple technique. Causes of mild regurgitation were technical and can be eliminated by accurate sizing of the prostheses and careful implantation. Specifically, mild mitral regurgitation, observed in 1 animal with each valve configuration, demonstrates the importance of avoiding leaflet redundancy, leading to folding on the one hand and (for F-SMV) disparity in flap chordae length on the other.

Our valve differs in a number of ways from commercially available stentless prostheses, such as the St Jude Medical Quattro (St Jude Medical, Inc, St Paul, Minn) quadricusp mitral valve. ${ }^{16,25-27}$ The Quattro prosthesis has a 

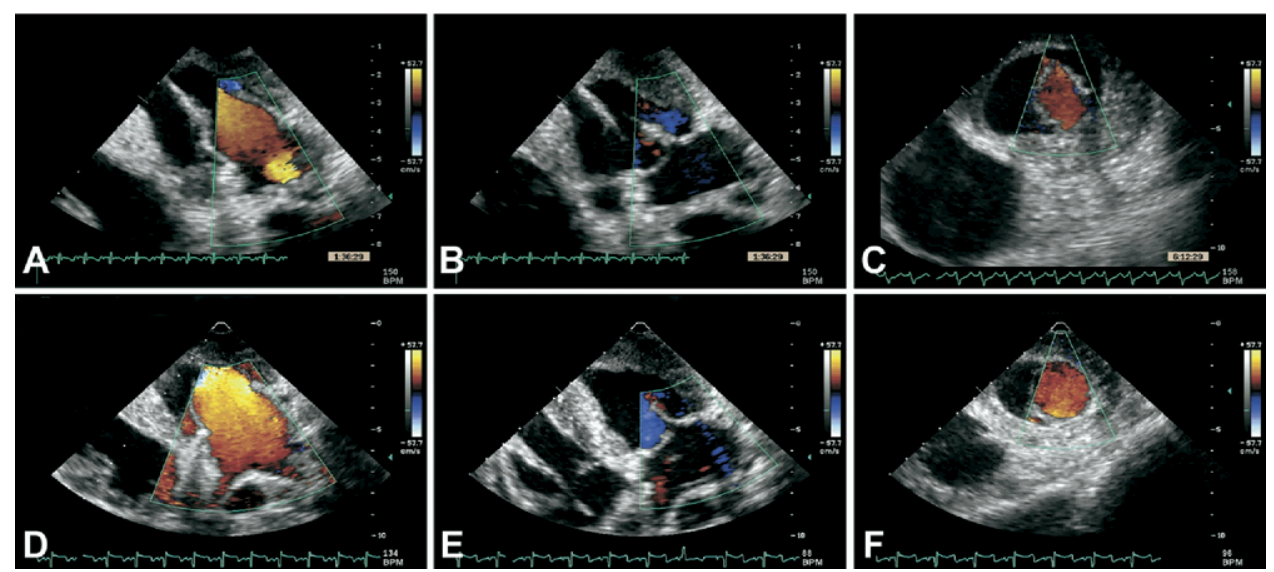

Figure 6. Postimplant epicardial color Doppler echocardiography during diastolic and systolic phases. A and B, SMV, 4-chamber view; C, short-axis view. D and E, F-SMV, 4-chamber view; F, short-axis view. Both bioprostheses show large valve orifice area with unrestricted central laminar flow and competent valve closure.

4-leaflet configuration, with a large pericardial tissue coaptation area that reduces risk of regurgitation. Each leaflet has a chordae-flap extension that occupies a large amount of LV space. We believe this quadricusp configuration leads to nonuniform opening and restricted transvalvular flow, as well as potential outflow obstruction in patients with a small LV cavity (such as occurs in mitral stenosis from rheumatic valve disease). It is this very setting that is the primary indication for use of a prosthesis. Our design differs more sharply from the Medtronic stentless porcine xenograft prosthesis (Medtronic, Inc, Minneapolis, Minn), ${ }^{13}$ whose subvalvular apparatus consists of a complex arrangement of chordae attached to 2 polyester tubes that are sutured to the tips of the papillary muscles. Coaptation seems sensitive to accurate length of these papillary muscle tubes. Matching donor and host anatomy is a problem that makes the surgical procedure technically complex, just as it does for the Biocor porcine stentless mitral valve ${ }^{28}$ (BioCor, Belohorizonte, Brazil). Our design also differs from that of the stentless mitral pericardial valve, ${ }^{29}$ which is fabricated on the operating room table with 2 square or trapezoidal pieces of autologous or bovine pericardium. The pericardial pieces are sutured together along their lateral margins, creating a valvular body of a modified cylinder or truncated cone. The lateral sutures are used as chordae to attach to the papillary muscles. This fabrication characteristic introduces uncertainties and makes it difficult to achieve reproducible, reliable function. Further, durability is uncertain because extensions of the lateral valve sutures are used to attach the chordae to the papillary muscle head. Our valve also differs from allograft mitral valves that suffer from complex and nonreproducible implantation techniques, ${ }^{30-32}$ particularly appropriate alignment of the subvalvular apparatus and secure and reliable papillary muscle anastomosis. ${ }^{33}$

\section{Acute Valve Performance}

By echocardiography, both SMV and F-SMV demonstrated good physiologic valve performance without mitral stenosis or LV outflow tract obstruction. Mean transvalvular pressure gradient was lower than that of other prosthetic valves. ${ }^{20-22,34}$ The increment in gradient with dobutamine stimulation was within the expected physiologic range.

\section{Postimplantation LV Function}

In acute animal models, interrupting annulus-papillary continuity impairs indices of LV contractile function, such as loadindependent slope of end-systolic pressure-volume loop and maximum rate of change of left ventricular pressure, ${ }^{1,2}$ and these recover to baseline when annulus-papillary continuity is reestablished. ${ }^{1}$ We did not observe a decrease in these indices acutely after insertion of either SMV or F-SMV. With stimulation, some indices increased significantly, although not as much as might be anticipated. However, the dobutamine dose was low $\left(0.5\right.$ or $\left.1.0 \mu \mathrm{g} \cdot \mathrm{kg}^{-1} \cdot \mathrm{min}^{-1}\right)$ because sheep hearts are sensitive to it; higher doses easily cause tachycardia, ventricular tachycardia, or ventricular fibrillation. Also, a low dose of norepinephrine was used in half the sheep at both rest and stimulation. Need for inotropic support following $\mathrm{CPB}$ may be linked to a depressed myocardial state leading to the lower-than-expected increase in contractility and cardiac output in response to stimulation.

\section{Limitations}

This is a report of an acute assessment of the design, development, and implantation of a new stentless valve prosthesis for the mitral position. It is only the first step in the ongoing process of testing the developmental concept of 
Table 1. Hemodynamic data at baseline and acutely postimplant at rest and with dobutamine stimulation

\begin{tabular}{|c|c|c|c|c|c|c|}
\hline & \multicolumn{3}{|c|}{ SMV } & \multicolumn{3}{|c|}{ F-SMV } \\
\hline & Baseline & Rest & Stimulation & Baseline & Rest & Stimulation \\
\hline HR (beats/min) & $96 \pm 9$ & $104 \pm 18$ & $145 \pm 10^{*}, \ddagger$ & $111 \pm 11$ & $116 \pm 16$ & $128 \pm 22^{*}$ \\
\hline CO (L/min) & $4.7 \pm 1.1$ & $3.2 \pm 0.9^{*}$ & $3.0 \pm 0.9^{*}$ & $5.4 \pm 0.5$ & $3.0 \pm 0.8^{*}$ & $3.2 \pm 0.7^{*}$ \\
\hline SV $(\mathrm{mL})$ & $50 \pm 14$ & $31 \pm 10^{*}$ & $21 \pm 6^{*}, \ddagger$ & $49 \pm 8$ & $27 \pm 8^{*}$ & $25 \pm 6^{*}$ \\
\hline LVEDP (mm Hg) & $8 \pm 2$ & $8 \pm 2$ & $6 \pm 2 \dagger, \ddagger$ & $6 \pm 2$ & $5 \pm 1 \S$ & $7 \pm 4$ \\
\hline SVR (dynes $\cdot \mathrm{s} \cdot \mathrm{m}^{-5}$ ) & $1500 \pm 460$ & $1970 \pm 840$ & $2700 \pm 1860^{\dagger}$ & $1290 \pm 220$ & $1870 \pm 580$ & $1890 \pm 430^{\dagger}$ \\
\hline PVR (dynes $\cdot \mathrm{s} \cdot \mathrm{m}^{-5}$ ) & $220 \pm 63$ & $240 \pm 131$ & $380 \pm 271$ & $128 \pm 118$ & $300 \pm 199$ & $290 \pm 164$ \\
\hline Mean AoP (mm Hg) & $87 \pm 13$ & $79 \pm 11$ & $80 \pm 14$ & $92 \pm 10$ & $77 \pm 9 \dagger$ & $91 \pm 12 \ddagger$ \\
\hline Mean CVP (mm Hg) & $3 \pm 4$ & $8 \pm 4^{*}$ & $6 \pm 4 \dagger$ & $6 \pm 4$ & $10 \pm 3^{*}$ & $9 \pm 4 \dagger$ \\
\hline Mean PAP $(\mathrm{mm} \mathrm{Hg})$ & $18 \pm 6$ & $22 \pm 3 \dagger$ & $22 \pm 3 \dagger$ & $19 \pm 6$ & $29 \pm 8^{*}$ & $28 \pm 8^{*}$ \\
\hline Mean PCWP $(\mathrm{mm} \mathrm{Hg})$ & $10 \pm 5$ & $15 \pm 4^{*}$ & $13 \pm 5 \dagger$ & $11 \pm 4$ & $20 \pm 4^{*}$ & $17 \pm 4^{*}$ \\
\hline Mean LAP (mm Hg) & $5 \pm 4$ & $13 \pm 3^{*}$ & $12 \pm 5^{*}$ & $11 \pm 4$ & $18 \pm 5^{*}$ & $17 \pm 5 \dagger$ \\
\hline
\end{tabular}

Values are expressed as mean $\pm \mathrm{SD}$.

$H R$, Heart rate; CO, cardiac output; SV, stroke volume; LVEDP, left ventricular end-diastolic pressure; SVR, systemic vascular resistance; PVR, pulmonary vascular resistance; $A o P$, arterial pressure; $C V P$, central venous pressure; $P A P$, pulmonary artery pressure; $P C W P$, pulmonary capillary wedge pressure; $L A P$, left atrial pressure. $* P<.001$ versus baseline. $\dagger P<.05$ versus baseline. $\ddagger P<.05$ versus rest. $\S P<.05$ SMV versus F-SMV at same data point.

the 2-valve configurations, the implantation techniques, valve performance, and hemodynamic response.

We recognize the inherent limitations of acute hemodynamic results. It is difficult to isolate the hemodynamic effects of the valve from hemodynamic impairment associated with $\mathrm{CPB}$ and transient cardiac ischemia.

\section{Conclusions}

We have developed a novel stentless bileaflet mitral valve in 2 configurations, each preserving annular-papillary muscle continuity by novel implantation techniques. Their configuration makes insertion easy and reproducible, although mild mitral regurgitation observed with 1 implantation with each configuration emphasizes the challenge of accurate measurements required for perfect valve function. Both demonstrate low transvalvular pressure gradients in acute animal studies. Further chronic study is needed to verify these results and evaluate the reliability of implantation procedures and the biocompatibility and durability of the valves.

Looking ahead, patients who are unsuitable for mitral valve repair are candidates for these valves. Choice of SMV or F-SMV would depend on extent of disease. SMV could be used for localized leaflet lesions, such as thickened leaflets causing mitral stenosis, enlarged or redundant regurgitant myxomatous leaflets, or localized vegetations, in which the subvalvular apparatus is not involved in the disease process and artificial chordae are not used. ${ }^{5}$ The F-SMV would be suitable for disease involving both the leaflets and subvalvular apparatus. Other applications include mitral leaflet extension or partial mitral valve replacement as "a part of the wide range of techniques of mitral valve repair" for which allografts have been proposed. ${ }^{20}$
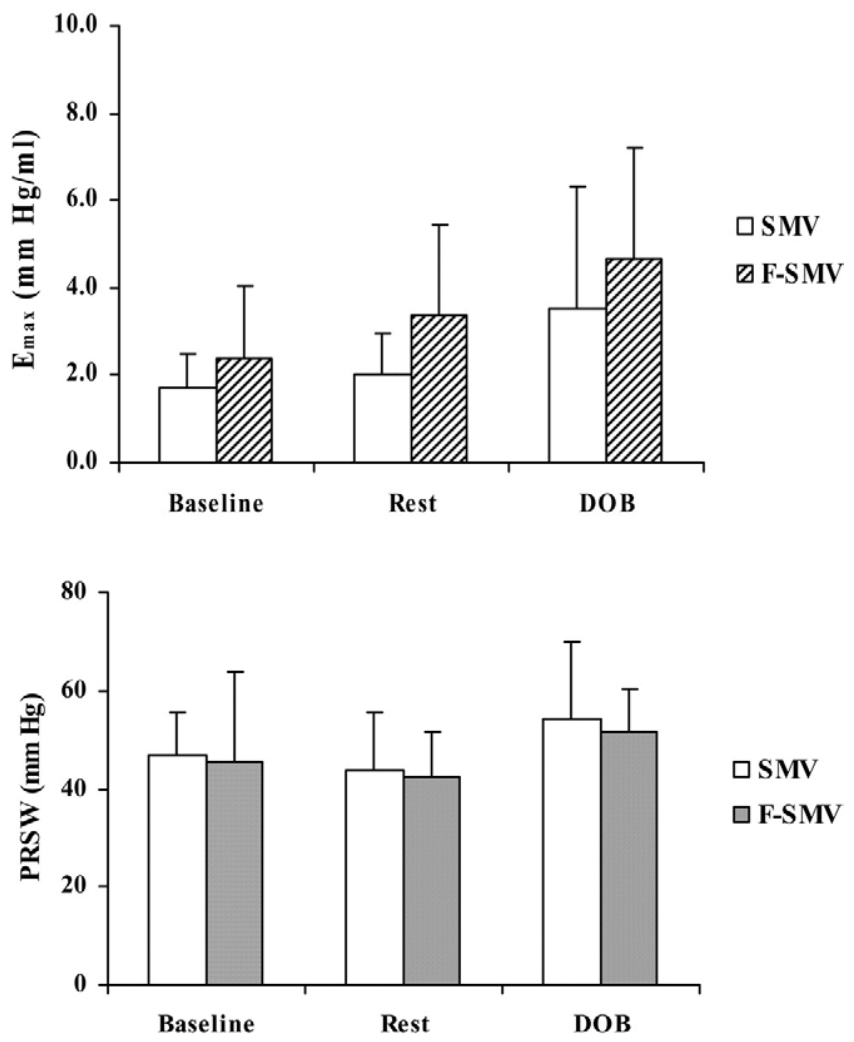

Figure 7. Changes in load-independent slope of end-systolic pressure-volume loop $\left(E_{\max }\right)$ and preload recruitable stroke work (PRSW). $E_{\max }$ (top) increased significantly with dobutamine stimulation in F-SMV group. Statistically significant changes in PRSW were not found at rest or with stimulation in either group. Bars represent 1 standard deviation. SMV, Stentless mitral valve; $F$ $S M V$, stentless mitral valve with flap chordae; DOB, dobutamine. 

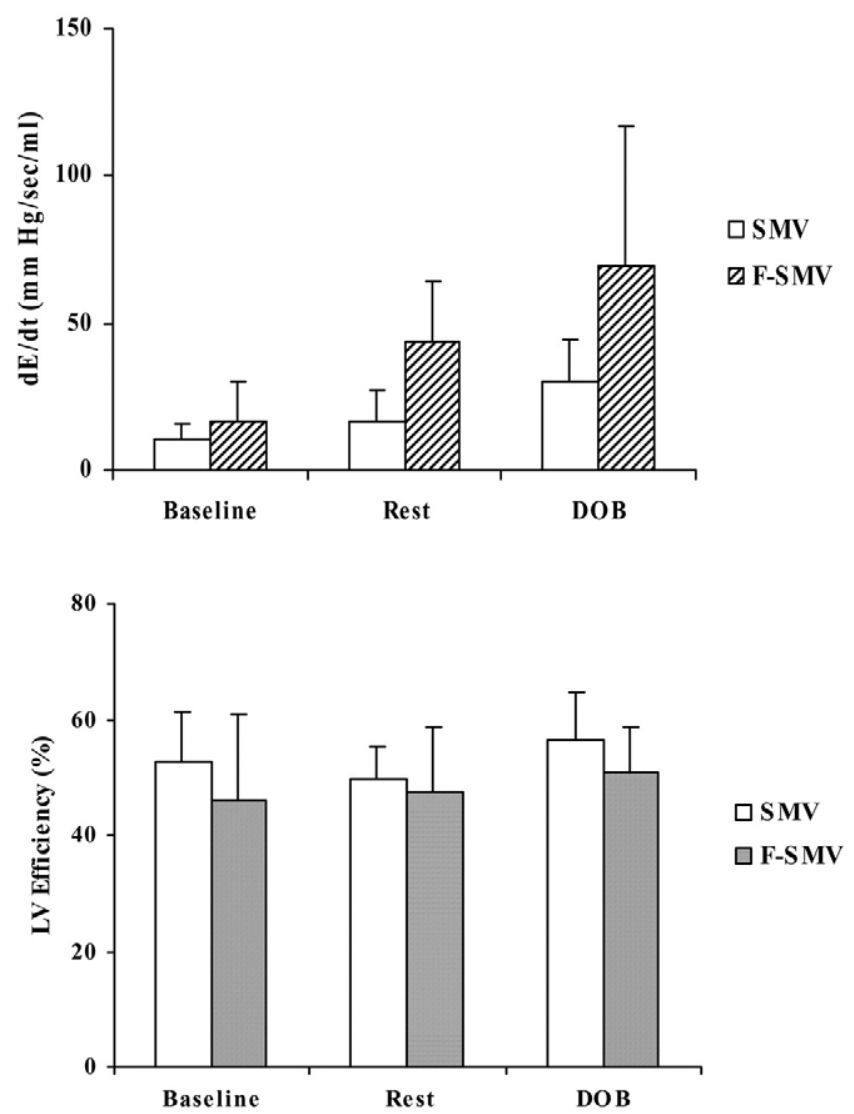

Figure 8. Changes in slope of maximum rate of change of pressureend-diastolic-volume relationship (dE/dt) and left ventricular (LV) efficiency. dE/dt (top) increased significantly with dobutamine stimulation in SMV group and at rest and with stimulation in F-SMV group compared with baseline. Statistically significant changes in LV efficiency (bottom) were not noted at rest or with stimulation in either group. SMV, Stentless mitral valve; F-SMV, stentless mitral valve with flap chordae; $D O B$, dobutamine.

We gratefully thank Cristiano Faber, MD, Hassan Nemeh, MD, Soren Schenk, MD, Masahiro Inoue, MD, PhD, Yoshio Ootaki, $\mathrm{MD}$, PhD, Jose A. Navia, MD, and Jorge Jordana for their invaluable help.

\section{References}

1. Sarris GE, Cahill PD, Hansen DE, Derby GC, Miller DC. Restoration of left ventricular systolic performance after reattachment of the mitral chordae tendineae. The importance of valvular-ventricular interaction. J Thorac Cardiovasc Surg. 1988;95:969-79.

2. Gams E, Schad H, Heimisch W, Hagl S, Mendler N, Sebening F. Importance of the left ventricular subvalvular apparatus for cardiac performance. J Heart Valve Dis. 1993;2:642-5.

3. Carpentier A. Cardiac valve surgery-the "French correction." J Thorac Cardiovasc Surg. 1983;86:323-37.

4. Cosgrove DM. Mitral valve repair in patients with elongated chordae tendineae. J Card Surg. 1989;4:247-52.

5. Duran CM. Surgical techniques for the repair of anterior mitral leaflet prolapse. J Card Surg. 1999;14:471-81.
6. Lillehei CW, Levy MJ, Bonnabeau RC Jr. Mitral valve replacement with preservation of papillary muscles and chordae tendineae. $J$ Thorac Cardiovasc Surg. 1964;47:532-43.

7. Komeda M, David TE, Rao V, Sun Z, Weisel RD, Burns RJ. Late hemodynamic effects of the preserved papillary muscles during mitral valve replacement. Circulation. 1994;90:II190-4.

8. Wasir H, Choudhary SK, Airan B, Srivastava S, Kumar AS. Mitral valve replacement with chordal preservation in a rheumatic population. J Heart Valve Dis. 2001;10:84-9.

9. Bishay ES, McCarthy PM, Cosgrove DM, Hoercher KJ, Smedira NG, Mukherjee D, et al. Mitral valve surgery in patients with severe left ventricular dysfunction. Eur J Cardiothorac Surg. 2000;17:213-21.

10. Lee EM, Shapiro LM, Wells FC. Importance of subvalvular preservation and early operation in mitral valve surgery. Circulation. 1996;94: 2117-23.

11. Westaby S, Horton M, Jin XY, Katsumata T, Ahmed O, Saito S, et al. Survival advantage of stentless aortic bioprostheses. Ann Thorac Surg. 2000;70:785-90; discussion 90-1.

12. Shomura Y, Tahta SA, Lansac E, Duran CM. Hemodynamic evaluation of a new stentless autologous pericardial mitral valve. Ann Thorac Surg. 2001;71:S315-7.

13. Dagum P, Green GR, Timek TA, Daughters GT, Foppiano LE, Tye TL, et al. Functional evaluation of the Medtronic stentless porcine xenograft mitral valve in sheep. Circulation. 1999;100:II70-7.

14. Vrandecic MO, Fantini FA, Gontijo BF, Oliveira OC, Martins IC, Oliveira MH, et al. Surgical technique of implanting the stentless porcine mitral valve. Ann Thorac Surg. 1995;60:S439-42.

15. Aybek T, Simon A, Dogan S, Greinecker GW, Moritz A. Two years' clinical experience with a quadrileaflet stentless bioprosthesis in the mitral position. J Heart Valve Dis. 2000;9:667-73.

16. Walther T, Walther C, Falk V, Diegeler A, Krakor R, Schneider J, et al. Early clinical results after stentless mitral valve implantation and comparison with conventional valve repair or replacement. Circulation. 1999; 100:II78-83.

17. Doty DB, Doty JR, Flores JH, Millar RC. Cardiac valve replacement with mitral homograft. Semin Thorac Cardiovasc Surg. 2001;13:35-42.

18. Kumar AS, Choudhary SK, Mathur A, Saxena A, Roy R, Chopra P. Homograft mitral valve replacement: five years' results. $J$ Thorac Cardiovasc Surg. 2000;120:450-8.

19. Gillinov AM, Cosgrove DM, Blackstone EH, Diaz R, Arnold JH, Lytle $\mathrm{BW}$, et al. Durability of mitral valve repair for degenerative disease. J Thorac Cardiovasc Surg. 1998;116:734-43.

20. Acar C, Tolan M, Berrebi A, Gaer J, Gouezo R, Marchix T, et al. Homograft replacement of the mitral valve. Graft selection, technique of implantation, and results in forty-three patients. $J$ Thorac Cardiovasc Surg. 1996;111:367-78; discussion 78-80.

21. Walther T, Falk V, Lehmann S, Walther C, Doll N, Bucerius J, et al. Hemodynamic evaluation of stentless mitral valve replacement. Artif Organs. 2002;26:847-50.

22. Timek TA, Lai DT, Tibayan FA, Dagum P, Daughters GT, Liang D, et al. Hemodynamic performance of an unstented xenograft mitral valve substitute. J Thorac Cardiovasc Surg. 2002;124:541-52.

23. Institute of Laboratory Animal Research, Commission on Life Sciences, National Research Council. Guide for the care and use of laboratory animals. Washington, D.C.: National Academies Press; 1996.

24. Diggle PJ, Heagerty PJ, Liang KY, Zeger SL. Analysis of longitudinal data. 2nd ed. New York: Oxford University Press; 2002.

25. Middlemost SJ, Manga P. The stentless quadrileaflet bovine pericardial mitral valve: echocardiographic assessment. J Heart Valve Dis. 1999;8:180-5.

26. Walther T, Lehmann S, Falk V, Walther C, Doll N, Uhlig B, et al. Early results with stentless mitral valve replacement. $J$ Heart Valve Dis. 2004;13:766-70; discussion 70-1.

27. Walther T, Walther C, Falk V, Kruger M, Dagge A, Diegeler A, et al. Stentless mitral valve replacement using the quattro valve. Semin Thorac Cardiovasc Surg. 1999;11:186-90.

28. Morea M, De Paulis R, Galloni M, Gastaldi L, di Summa M. Mitral valve replacement with the Biocor stentless mitral valve: early results. J Heart Valve Dis. 1994;3:476-82. 
29. Deac RF, Simionescu D, Deac D. New evolution in mitral physiology and surgery: mitral stentless pericardial valve. Ann Thorac Surg. 1995;60:S433-8.

30. Rastelli GC, Berghuis J, Swan HJC. Evaluation of function of mitral valve after homotransplantation in the dog. J Thorac Cardiovasc Surg. 1965;49:504-74.

31. O'Brien MF, Gerbode F. Homotransplantation of the mitral valve: preliminary experimental report and review of the literature. Aust $N Z$ J Surg. 1964;34:81-8.

32. Hubka M, Siska K, Brozman M, Holec V. Replacement of mitral and tricuspid valves by mitral homograft. J Thorac Cardiovasc Surg. 1966;51:195-204.

33. Acar C. Mitral valve homograft. Adv Card Surg. 1997;9:1-13.

34. Zabalgoitia M. Echocardiographic recognition and quantitation of prosthetic valve dysfunction. In: Otto CM, editor. The practice of clinical echocardiography. 2nd ed. Philadelphia: WB Saunders, 2002. p. 525-50.

35. Suga H, Sagawa K, Shoukas AA. Load independence of the instantaneous pressure-volume ratio of the canine left ventricle and effects of epinephrine and heart rate on the ratio. Circ Res. 1973; 32:314-22.

36. Suga H, Sagawa K. Instantaneous pressure-volume relationships and their ratio in the excised, supported canine left ventricle. Circ Res. 1974;35:117-26.

37. Little WC, Cheng CP, Mumma M, Igarashi Y, Vinten-Johansen J, Johnston WE. Comparison of measures of left ventricular contractile performance derived from pressure-volume loops in conscious dogs. Circulation. 1989;80:1378-87.

38. Suga H. Ventricular energetics. Physiol Rev. 1990;70:247-77. 


\section{Appendix E1: Surgical Procedures and Baseline Measurements}

The left carotid artery and external jugular vein were isolated through a lateral vertical neck incision. The artery was cannulated with an $8 \mathrm{~F}$ sheath. A conductance catheter (SPC-562, Millar Instruments, Inc, Houston, Tex) with 2 Millar pressure sensors was inserted into the left ventricle and aortic root to record LV volume and pressure and aortic pressure; the catheter was positioned so that all 5 segments yielded good conductance signals. Blood conductivity was calibrated in the Leycom sigma-5DF signal-conditioner processor (CardioDynamics, Zoetermeer, The Netherlands). A thermistor-tip balloon catheter (Criticath SP5507 TD catheter; Becton Dickinson Infusion Therapy System, Inc, Sandy, Utah) was inserted from the external jugular vein into the pulmonary artery to monitor pulmonary artery and central venous pressures, positioned so that balloon inflation produced pulmonary capillary wedge pressure.

A left thoracotomy was performed and the pericardium opened longitudinally. A 20-mm Transonic flow probe (Model No. 20A165, Transonic Systems, Inc, Ithaca, NY) was placed on the ascending aorta and connected to a flow meter (Model T106, Transonic Systems) to monitor flow and forward cardiac output continuously. A fluid-filled pressure monitor catheter was inserted into the left atrium. An umbilical tape was snared around the inferior vena cava (IVC).

Hemodynamic indices were recorded at steady state and after transient IVC occlusion to obtain LV pressure-volume loops under various preloads before prosthesis implantation (baseline). Ventilatory support was transiently stopped during data acquisition periods. Data were digitized in real time at $200 \mathrm{~Hz}$ (PowerLab; AD Instruments, Inc, Mountain View, Calif) for subsequent analysis. Epicardial 2-D echocardiography equipped with harmonic imaging was performed to evaluate LV end-diastolic (LVEDV) and endsystolic (LVESV) volumes for calibration of LV volumes obtained by conductance catheter, using biplane Simpson's rule. After baseline data acquisition, the conductance catheter, flow probe, and left atrial catheter were removed to prepare for cardiopulmonary bypass and prosthesis implantation.

\section{Appendix E2: Extracting Hemodynamic Indices}

Data analysis was performed with a custom-made Visual Basic program using Excel software (Excel 2000; Microsoft Corporation, Redmond, Wash). After calibrating conductance LV volume data with echocardiographic data, LV ejection fraction and stroke work $(\mathrm{LVSW}=[\mathrm{LVEDV}-\mathrm{LVESV}] \times[\mathrm{LV}$ end-systolic pressure - LV end-diastolic pressure] $\times$ 0.0136) were calculated and maximum and minimum $\mathrm{LV}$ pressure derivatives $\left(\mathrm{LV}_{\max } \mathrm{dP} / \mathrm{dt}\right.$ and $\mathrm{LV}_{\text {min }} \mathrm{dP} / \mathrm{dt}$ ) determined.

Load-independent indices of LV contractile function were obtained from LV pressure-volume loops drawn using conductance data. Slope $\left(\mathrm{E}_{\max }\right)$ of the end-systolic pressure-volume relationship was obtained under various preloads using iterative linear regression. ${ }^{35,36}$ Slopes of LVSW - LVEDV (preload recruitable stroke work, PRSW) and $\mathrm{LV}_{\max } \mathrm{dP} / \mathrm{dt}$ - LVEDV (slope of maximum rate of change of pressure-end-diastolic volume relationship, dE/dt) relationships were also evaluated. ${ }^{37}$ The area inside the pressure-volume loop expresses external work. Total energy generated by the LV was approximated as the pressure-volume area, which was circumscribed by the end-systolic pressure-volume relationship, end-diastolic pressure-volume relationship, and systolic trajectory of the pressure-volume loop. LV mechanical efficiency was evaluated by calculating the ratio of those areas (LV efficiency $=$ external work/pressure - volume area). ${ }^{38}$ 
Table E1. Left ventricular function at baseline and acutely postimplant at rest and with dobutamine stimulation

\begin{tabular}{|c|c|c|c|c|c|c|}
\hline & \multicolumn{3}{|c|}{ SMV } & \multicolumn{3}{|c|}{ F-SMV } \\
\hline & Baseline & Rest & Stimulation & Baseline & Rest & Stimulation \\
\hline LVEDV (mL) & $66 \pm 17$ & $54 \pm 13$ & $44 \pm 10 \dagger$ & $55 \pm 16$ & $34 \pm 13^{*}, \S$ & $25 \pm 8^{*}, \pm, \ddagger$ \\
\hline $\operatorname{LVEF}(\%)$ & $56 \pm 3$ & $51 \pm 5$ & $52 \pm 5$ & $50 \pm 4 \S$ & $42 \pm 4 \S$ & $47 \pm 8$ \\
\hline $\mathrm{LV}_{\max } \mathrm{dP} / \mathrm{dt}\left(\mathrm{mm} \mathrm{Hg} \cdot \mathrm{s}^{-1} \cdot 10^{-2}\right)$ & $11.8 \pm 2.4$ & $13.9 \pm 3.9$ & $20.9 \pm 4.7 \dagger, \ddagger$ & $13.2 \pm 3.4$ & $15.5 \pm 2.5$ & $22.2 \pm 7.0 \dagger, \ddagger$ \\
\hline $\mathrm{LV}_{\min } \mathrm{dP} / \mathrm{dt}\left(\mathrm{mm} \mathrm{Hg} \cdot \mathrm{s}^{-1} \cdot 10^{-2}\right)$ & $-18 \pm 3.9$ & $-13.1 \pm 4.2 \dagger$ & $-14.9 \pm 3.6$ & $-20.5 \pm 4.2$ & $-11.6 \pm 0.8^{*}$ & $-16.2 \pm 4.0 \dagger$ \\
\hline
\end{tabular}

Values are expressed as mean \pm SD.

$L V E D V$, Left ventricular end-diastolic volume; $L V E S V$, left ventricular end-systolic volume; $L V E F$, left ventricular ejection fraction; $L V_{\text {max }} d P / d t$, maximum rate of change of left ventricular pressure; $L V_{\min } d P / d t$, minimum rate of change of left ventricular pressure; $L V S W$, left ventricular stroke work. $* P<.001$ versus baseline. $\dagger P<.05$ versus baseline. $\ddagger P<.05$ versus rest. $\S P<.05$ SMV versus F-SMV at same data point.

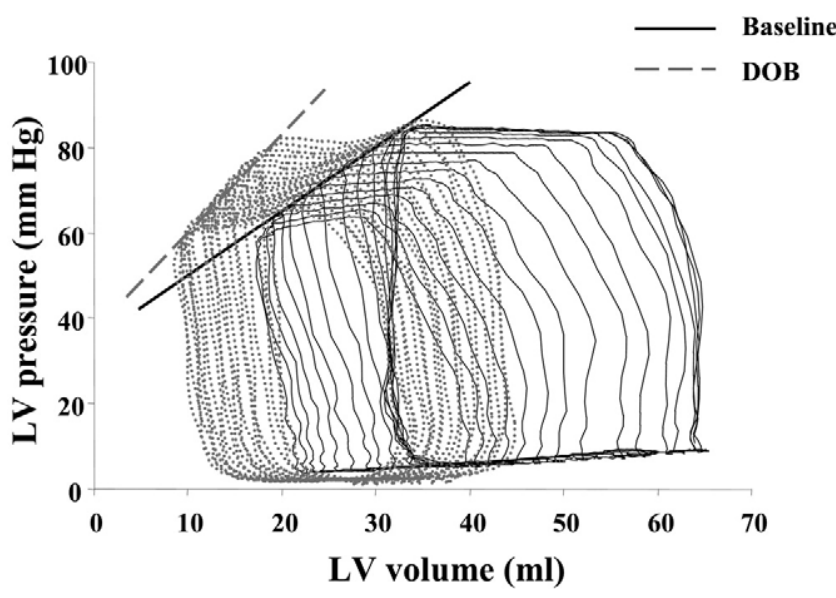

Figure E1. Representative left ventricular pressure-volume loops acquired at baseline and with dobutamine stimulation. $L V$, Left ventricular; $D O B$, dobutamine. 